\title{
Types of Learning (Individual vs. Cooperative) in Mobile Devices and Their Effect on the Development of Skills of Using Google Educational Applications and Self-Regulated Learning
}

\author{
Dr. Amal Karam Khalifa ${ }^{1}$ \\ Dr. Mohamed Hassan Ragab Khalaf ${ }^{2}$
}

\begin{abstract}
:
The study aims to determine the most appropriate type (individual Vs. cooperative) in mobile devices and their effect on the development of skills of using Google educational applications and self-regulated learning. The educational Google apps skills in this research are: Google Docs, Google slides, Google Drawing, Google Forms and Google Sheets. The design of Extended One Group Pretest Posttest Design was used in this research. The basic sample of the research included 60 of master's degree students in the Faculty of Specific Education, Alexandria University. The sample was divided in two equal groups, each one contained of 30 students. Group 1 was taught in the individual method, while group 2 was taught in the cooperation method. The two groups were selected and distributed in randomly. It was found out that the priority of group 2 in both exams, and the statistically significant positive correlation between the scores of students in each of the skills checklist and self-regulated learning scale in the both two groups (individual vs. cooperative).
\end{abstract}

Keywords: Individual Learning, Cooperative Learning, Mobile Learning, Google Educational Applications, Self-regulated Learning.

\section{Introduction:}

Today, learners are shifting their learning styles and methods from traditional learning to technology-based learning. They can access convenient communication, and it is easy to communicate with one another anytime, anywhere, individually and cooperatively, using various mobile devices (Kook, 2014), like Smartphones and other mobile digital devices, such as tablets, which can be surprisingly useful didactic resources for developing subjects in both distance and face-to-face university studies (Johnson et al., 2014).

\footnotetext{
1 Associate Professor Instructional Technology, Department of Instructional Technology, Faculty of Specific Education, Alexandria University, Egypt.dr_amalkk @yahoo.com

2 Assistant Professor, Department of Instructional Technology, Faculty of Education, Alexandria University, Egypt. and Assistant Professor, Department of education \& psychology, Faculty of Science \& Arts in El Guryat, Jouf University, Saudi Arabia. moo4hr@yahoo.com.
} 
Mobile learning (ML) is a method of using wireless and mobile technologies in education. As mobile technology becomes increasingly widespread, it is likely to offer various learning opportunities. Thus, mobile experts and educational technologists predict that the evolution and advancement of mobile technology will continue to accelerate in learning (Kook, 2014).

Cochrane and Bateman (2010) have emphasized that the benefits of ML, especially the portability, flexibility, and context of mobile technologies, which facilitate learning, promote cooperation, and encourage both independent and cooperative learning for Long life learning. Wireless mobile technologies have given individuals the opportunity to work cooperatively and stay connected. Students can be organized into groups, seeking new knowledge, sharing learning materials through mobile apps or/and with face-to- face communication, and continuing their learning process beyond the traditional learning (Wang, 2013).

Most top universities, such as Phoenix University, Stanford University and Florida International University, are experimenting with digital policies that allow for more freedom in interactions among students when working on projects and assessments in order foster cooperation and reinforce real-world skills (Johnson et al., 2014).

Therefore, the goal of integrating mobile technologies into university subjects stems from the high penetration of such devices all around the world and their potential didactic use in ubiquitous environments.

There are several apps in mobile rises continuously every day, due to the high demand for applications by users, One of these applications Google Apps. The Google Apps Education Edition are suitable for universities; they help students and teachers store files and cooperate on documents, spreadsheets, and presentations in real time from school or home in a "closed campus" online environment. The use of these tools is basically optional and is intended to provide an approved and supportive alternative to "consumer" Google accounts (Tenally, 2014).

There are several tools for fostering cooperation, which allow students to work on projects simultaneously including Google Tasks and Google Docs, Facebook, and Google Hangout. As a research resource, Google Scholar allows students to find reputable journal articles and books. Google Drive was the most popular application for work on group projects because it utilizes the Cloud, which makes documents easily accessible to 
everyone, anywhere. This enables anyone in the group to work on the document in real time, which is very conducive to a cooperative effort. Other Google products identified being used for cooperation were Google Docs and Google Hangout (Hochstrasser, 2014).

Useful web-applications currently exist and will continue to grow in number. When properly used, technology can "foster student engagement in the learning process, decrease attrition, enhance learning outcomes and improve student satisfaction" (Revere and Kovach, 2011), so learners must be capable of taking complete control of their own learning.

In other words, learners who are inherently motivated and take charge of their learning have, to some degree, already achieved selfregulation. It is believed that self- regulated learners successfully utilize learning strategies such as goal setting, planning and monitoring throughout their learning process. Fortunately, self-regulated learning is viewed as an academic skill as opposed to an intellectual ability or a scholastic performance skill (Stephens, 2009).

As Pintrich, Ryan \& Deci (2000) contend, researchers have openly confirmed that learners who use self-regulated learning strategies and selfdirected methods to learn accomplish more and are more pleased with their work.

In addition, Google Apps can help learners to become better placed to hear about effective ways to learn; and able to share experiences, insights and news. Sustainably lifelong learning styles depend on the emergence of rising generations of competent or 'self-regulated' learners.

Despite the advantages of using Google Apps in education through mobile, a multitude of postgraduate students possess mobile devices and have Google applications on mobile, but it is not used in education. On the contrary, they use these applications in random tasks. The result is the failure to regulate their learning and thus losing many self-learning skills, so from here the research problem stems and it can be discussed in the following section.

\section{Context of the problem:}

The current researchers have observed through their work in the teaching of master's courses in general and during teaching the course name of "new trends in educational technology", in particular at the Department of Education Technology, Faculty of Specific Education, Alexandria University, that there is a problem in the interaction with the students regularly. Since they are students from the State of Kuwait who have joined a master's degree Program at Alexandria University, they find much 
difficulty in regularly attending their classes, being obliged to travel to Kuwait every week.

In the beginning of the semester 2014/2015, the researchers applied a questionnaire to check the opinions of master's students from Kuwait on the use of e- learning styles. The results of questionnaire revealed that there is a high agreement rate among students $(86.19 \%)$ on adopting mobiles and their applications as a means of communication among each other and between them and the lecturer, especially in teaching and carrying out and using activities and tools of assessment.

Among the applications that have been agreed on for use in training students is "WhatsApp" to send videos and images in order to facilitate learning and participation among students. The main advantage of this application is that it is available through the mobile devices carried along by all students.

ML is the most appropriate method in solving the problem of the current research, where the researchers aim to develop the skills of using the google apps during the maintained course.

Therefore, the present research attempts to find out the difference between the two types of learning (individual vs. cooperative) in mobile devices and their effect on the development of skills of using Google educational applications and self-regulated learning.

\section{Research questions:} follows:

The main question of the present research can be formulated as

What is the effect of the two types of Learning (Individual vs. Cooperative) in Mobile Devices on Their Effect on the Development of Skills of Using Google Educational Applications and Self-Regulated Learning?

From this question, three sub-questions branch:

1 - What is the effect of the two types of learning on the development of skills of using Google educational applications?

2-What is the effect of the two types of learning on the development of self- regulated learning?

3-What is the significance of the correlation between the scores of students in each of the checklist of the google Apps skills and selfregulated learning scale?

\section{Objectives of the research:}

The study aims to determine the most appropriate type (individual vs. cooperative) in mobile devices and their effect on the development of skills of using Google educational applications and self-regulated learning. 


\section{The importance of the research:}

The present study derives its importance from the following points:

1-Proposing a Mobile Learning Model which determines as an example for teaching of other decisions.

2-It may help to conduct research related to the design variables and application of Mobile Learning Model and measure their impact on the development of the skills to use various electronic educational applications.

\section{The Scope of the research:}

The study was confined to:

1-Objective limits: designing an instructional unit entitled "skills of using educational Google apps" introduced within course "new trends in educational technology"; the module contained use of some educational Google apps skills like Google Docs, Google slides, Google Drawing, Google Forms and Google Sheets.

2-Determining the percentage of agreement (between researchers and specialists and educators) that can be relied upon to accept student performance of skills of using Google applications for educational purposes by the percentage of $75 \%$ of the total score for the checklist after consulting a jury.

3-Human limits: master's students

4-Spatial limits: Faculty of Specific Education, Alexandria University

5-Temporal limits: the second semester of the academic year 2014/2015.

\section{The hypotheses of the research:} formulated:

By reviewing the literature, the following hypotheses can be

1 - There is no significant difference at the level of $(\alpha \leq 0.05)$ between mean scores of students of the two experimental groups in the checklist of the google Apps skills due to the impact of the difference between the two types (Individual \& Cooperative) in mobile devices.

2 -There is no significant difference at the level of $(\alpha \leq 0.05)$ between mean scores of students of the two experimental groups in the selfregulated learning scale due to the impact of the difference between the two types (Individual \& Cooperative) in mobile devices.

3 -There is no significant difference at the level of $(\alpha \leq 0.05)$ between mean scores of students of the two experimental groups in the checklist and the self-regulated learning scale.

\section{Research methodology:}

The Quasi-experimental type was used to test the validity of 
hypotheses and answer the questions of the research.

\section{The experimental design of the research:}

In the light of the first independent variable, "the two types of learning (individual vs. cooperative) in mobile devices" and dependent variable "skills of using Google educational applications and self-regulated learning" the design of Extended One Group Pretest Posttest Design were used in this research. Table (1) illustrates the experimental design:

Table (1): The experimental design

\begin{tabular}{ccccc}
\hline Group & No. Prior Measurement & Experimental Treatment & $\begin{array}{c}\text { post } \\
\text { Measure } \\
\text { ment }\end{array}$ \\
\hline $\begin{array}{c}\text { The first } \\
\text { experiment } \\
\text { al Group }\end{array}$ & $\begin{array}{c}\text { Apply the individual learning in } \\
\text { mobile devices and Its effect on }\end{array}$ & \\
1-checklist. & $\begin{array}{c}\text { Google educational applications } \\
\text { the development of skills of using }\end{array}$ & $\begin{array}{c}\text { 1-Checkl } \\
\text { ist. }\end{array}$ \\
$\begin{array}{c}\text { The Second } \\
\text { experiment } \\
\text { al Group }\end{array}$ & $\begin{array}{c}\text { 2- Self regulated } \\
\text { Scale. }\end{array}$ & $\begin{array}{c}\text { Apply the cooperative learning in } \\
\text { mobile devices and Its effect on } \\
\text { the development of skills of using } \\
\text { Google educational applications } \\
\text { and self-regulated learning }\end{array}$ & $\begin{array}{c}\text { ed } \\
\text { scale }\end{array}$ \\
\hline \hline
\end{tabular}

\section{Research Terminology:}

The following terms are considered crucial by the researchers based on several studies, such as (Norton Radstock College, 2010; Barak, 2010; Paul, 2007; Stephens, 2009; Wang, 2014; Ally, 2009; Järvelä, 2007).

\section{M-learning:}

The ability to promote a robust interaction and communication among students, instructors or institution enabling them to contribute, participate and access the learning materials via mobile devices. Moreover, Mobile Learning is based on the exploitation of everywhere handheld technologies, together with wireless and mobile phone networks, to facilitate, support, enhance and extend the reach of teaching and learning resources.

\section{Self-regulated learning:}

Is a learning process which involves goal setting, strategy implementation, self- monitoring and self-assessment in order to perform a specific task, in other words, SRL refers to the self-directed process through which learners transform their mental abilities into academic skills.

\section{Google Apps:}

Google Apps is a collection of web-based programs and file storage 
systems that run via a web browser, without requiring users to purchase or install software. Users can simply sign into the service to access their files and the tools to manage them. Examples of Google applications that we apply in this research include Google Docs, Google slides, Google Drawing, Google Forms and Google Sheets.

\section{Cooperative learning:}

Cooperative learning is an instruction method based on students working in small-sized groups to accomplish shared learning goals.

\section{Literature Review: \\ Mobile learning:}

Over the past two decades, technology devices have become mobile portable and networked, to the extent that they have become pervasive in everyday life. In other words, the use of mobile devices has become common among a wide range of age groups owing to both affordability and availability.

Infrastructure, content, and resources related to the integration of mobile devices into learning environments, and ML, though undertheorized in teacher education, have been subject to significant investments (Kearney \& Maher, 2013). Despite the huge growth and potential of the $\mathrm{W} / \mathrm{H}$ devices and networks, wireless e-learning and $\mathrm{ML}$ are still in their infancy in the context of higher education.

Motiwalla (2007) sees that the existing technologies and extending the learning beyond the classrooms and homes from remote places, where students do not have access to computers and the Internet because wireless devices are highly individualized and cooperative communication. In addition, as Keser (2011) mobile- supported cooperative learning assists individuals to operate as teams in a common project or task.

Huang, Huang and Hsieh (2008) examined the integration of digital note taking (mobile annotation) systems into cooperative learning. In the study, they tried to create cooperative environments with using one of the cooperative learning methods, wireless communication tools and digital note taking systems. A wireless device provides instant gratification to students by allowing them to interact with their instructors and other students in the same course, and to access course materials from wherever (or anywhere) they have wireless connectivity.

BenMoussa (2003) identified several advantages of mobile connectivity. First, mobile applications generally avail users to control or filter the information flow and communication through the wireless phones and handheld devices, bearing in mind that these devices are usually highly 
personalized. Second, mobile connectivity improves cooperation through real-time or instant interactivity, regardless of time and location, resulting in better decision making. Finally, mobile connectivity enhances customer orientation, since users gain better access to their service providers and do a better job by balancing their work life through a more productive use of time. These advantages can prove equally useful for improving the learning environment.

Cheon et al (2012) listed other advantages. Mobile-based learning enables teachers and learner's ubiquitous and seamless access to information. Convenience, expediency, and immediacy are invaluable to teachers and enhance students' learning. These features provide opportunities for individualized, situated, cooperative, and informal learning situations without being limited to classroom contexts.

Baarn (2014) regarded flexibility, adaptability and ubiquity as allowing the student to take an active and critical role in the construction of his own knowledge, which enables the acquisition and development of basic skills in a significant way for life. He focused on the estimation of the level of quality of the teaching that is given in a broad, flexible and dynamic, context like that provided by mobile devices. He maintains that it is important to find out to what extent the methodology facilitates the students' integrated acquisition of three fundamental dimensions:

1-The cognitive dimension (the necessary knowledge, skills and abilities for the control, regulation and meaningful processing of information)

2-The ethical-social dimension (values, attitudes of responsibility, commitment, social skills and abilities)

3-The affective-emotional dimension (feelings of confidence, security, curiosity, interest, motivation).

Therefore, the use of mobile technology in education has relatively important benefits in students' learning. These assists include the following:

1- Concerning motivation, the student's personal interest in the task seems to increase as does their activity during studying.

2- Concerning social skills, it improves the cooperation work of the student as a member of the group, interpersonal communication and the use of empathy with others. It also enhances responsibility and personal commitment to the tasks and duties given to the group.

3- Concerning cognitive skills, the students increase their creativity in the production of new ideas and content, they improve the processes of acquisition of information and significantly develop the capacities of 
analysis, synthesis and evaluation of information (Navaridas, et al 2013) As a result, ML has become a crucial component in developing learning strategies for use in higher education. By using strategies that incorporate ML, educationalists may achieve better outputs from classes (Joongkak, 2014). Professors are required to adapt resources to their students' context in order to improve didactic activities and to reinforce the traditional learning process in higher education using the principles of mobile learning and ubiquitous digital environments. Given the significance of such services, the university's implementation of ubiquitous mobile learning could likewise be used as a reminder for students of their educational activities by providing them with the ability to access curricular content or participate with other students anytime and anywhere. University staffers may support such projects by designing simple applications that aim at developing cooperative efforts and curricular content for their students, thus offering more opportunities to access information and promote interaction among students. Moreover, didactic applications on mobile phones also indicate that students find them highly useful for their learning both by enhancing the subject's development, and by fostering cooperative work regardless of a student's age and gender (Vazquez-Cano, 2014).

According to Keskin and Metcalf (2011), there are nine theories of learning that can be examined through the lens of a mobile environment: Behaviorist, cognitivist, constructivist, situated learning, problem-based learning, context awareness learning, socio-cultural theory, cooperative learning, and conversational learning. Each of these theories has a different perspective, and mobile devices are well suited to applications of those theories. For example, cooperative learning seeks to promote learning using active participation and communication between students. This can be accomplished with multiple Web 2.0 tools, social networks, mobile educational gaming, e-mail, or mobile video conferencing (Fuegen, 2012).

The influence of using mobile communication technologies in learning environments has been empirically investigated in several studies, which concluded that they assist in enhancing availability and accessibility of information networks by engaging students in learning-related activities in diverse physical locations, and enhancing communication and cooperative learning among Learners (Rau, 2008). the use of mobile technologies and multimedia increases the interest of students, helping them to learn while they are entertained. The mobility functionality of the devices means that exercises can be done anytime and anywhere, thus 
promoting the participation of the stakeholders in the learning process and the socialization of the students (López, et al., 2013). Similarly, the results of Trisha's (2013) study confirmed that the mobile devices facilitate communication through intellectual capabilities and decisions; they should be a part of every pre-service teachers' learning experience. As Jeffrey (2014) contends, educators are apt to develop best practices to effectively incorporate mobile learning into educational pedagogies.

\section{Cooperative learning}

In higher education, much effort has been made to find new methods and ways to support individual student learning to achieve effective cooperation (Järvelä, 2007). Software modules have been prepared to collect, filter and store location information about students, and derive group membership information that can be offered as contextual information to applications. Based on group membership information, an "instant cooperation". (Messeguer, 2008) application provides instant messaging and file sharing automatically restricted. The design has also been applied to another existing synchronous cooperative application.

Based on social constructivism, cooperative learning responds to the meaningful learning in a society where people focus more on teamwork. Cooperative learning also encourages instructors to move toward studentcentered learning with cooperative technologies. Cooperation is the focus of most social constructivism models. Students are required to work together in groups to complete tasks collectively toward academic goals (Ford, Bowden, \& Beard, 2011).

Successful cooperative learning includes two crucial elements: (1) the learning groups must promote the active learning of members through social interactions and discussions among; and (2) before the instruction, teachers should carefully design and arrange the course materials and provide the professional knowledge and guidance needed by the learners. In this type of learning, group members are assigned different responsibilities, and share each other's learning accomplishments. Through social interaction, they can convey their understanding of certain concepts, assist each other, and jointly acquire new knowledge (Huang, 2014).

\section{Google apps:}

Google apps is different from mobile application, most frequently referred to as an app; it is a type of application software designed to run on a mobile device, such as a smartphone or a tablet computer. Mobile applications frequently serve to provide users with similar services to those 
accessed on PCs as well as access to internet-based resources and portable media players, GPS navigation, digital cameras and eBook readers, etc. (Shunye, 2014).

A mobile application also may be known as an app, Web app, online app, iPhone app or smartphone app" (Rana, 2013, p.13). Internet access and interactivity have increased interest in integrating these technologies into the instructional environment. Therefore, Google application is useful for organizing and sharing classroom lesson plans that can be regarded by students immediately without having to login to a management system. Gmail, for example, allows a class group to be formed where students and instructor can communicate simultaneously in real time.

In addition, as for work on group projects, Google Drive was the most popular application, Google Docs and Google Hangout, which is a live, visual and audio-conferencing service for multiple people. Some people even used Google Scholar to look up sources that are more credible. Digital textbooks were the norm for these students. They were less expensive and have a search quality that makes looking up and locating topics easy (Jeffrey, 2014).

\section{The targeted google Apps in this research:}

\section{1- Google Docs:}

They can create rich document formats with images, tables, equations, drawings, links, etc. They can also gather input and manage feedback and allow social commenting. Being a single account, a major advantage of Google Docs is that it allows users to create websites (Google Sites) and blogs (Blogger) through the same profile, so participants will need to create an account associated with a specific email address. Nevertheless, there are several features available through Google Docs that are ideal for engaging students in peer assessment. For instance, users can share files for viewing and editing, make comments, chat while working, and create specific forms (surveys, inventories, and tests) to gather and share feedback. Users can publish forms online, or solicit participation through email notification (Denton, 2012).

Tenally's (2014) study focused on the fact that teachers can use Google Docs to facilitate group projects and use the history tool to see the level of participation of each student in a group. Teachers are thus able to give feedback to students directly in documents shared with a teacher. Submitting assignments will be as easy as sharing the file in Google Docs with the teacher, as students will have an additional opportunity to ask a teacher question electronically, helping students learn to communication in 
a real-life environment. Users can easily upload and share files that support popular formats such as .doc, and .pdf. Smarter commenting, better feedback Google Docs' intuitive commenting feature allows for instructor and cooperator feedback.

\section{2- Google slides:}

It creates beautifully designed slides with a presentation editor, which supports embedded videos, animations and dynamic slide transitions. It can also be used to publish presentations on the web so anyone can view them or share them privately. Students use the slide to write responses at the same time, and then present the results to the whole class. During presentations, the instructor can inspect specific slides and call upon students for explanations, or revisions.

\section{3- Google Drawing:}

Students can create an image in class is to represent information visually. For example, students can draw a flow chart to show steps for solving a problem or completing a task. Similarly, students can create these diagrams cooperatively, through the sharing function, or publish them online as a web page.

\section{4- Google Forms:}

Is a convenient way for instructors and teachers to gather data to assess student progress, classroom climate, or both, A form can be published online as a separate web page or embedded into a learning management system such as Blackboard or Moodle. Results from Google Forms can be easily automatically downloaded as a Google Spreadsheet for future analysis (Denton, 2012).

\section{5- Google Sheets:}

They allow students to keep and share lists, track projects, analyze data and track results with our powerful spreadsheet editor. They can also make use of tools, such as advanced formulate, embedded charts, filters and pivot tables to obtain novel perspectives on the data. Therefore, Bonham (2011) employed Google Spreadsheet and Forms to collect and graph data points from students during a laboratory experiment.

Google is currently developing training materials for the Google Apps Education Edition that administrators can use to train teachers (Dessoff, 2010). Every application is accessible on mobile devices. Therefore, Google apps are used in communities of learners; they constitute the base for self-regulated of learning. In an educational context, the teacher's role is to provide criteria that students can use to evaluate their learning outcomes. 


\section{Self-regulated learning (SRL):}

Self-regulated learning concerns the way learners develop learning skills and use learning skills effectively. Therefore, self-regulated learners are responsible for their own learning by choosing and setting goals, using individual strategies in order to monitor, regulate and control the different aspects influencing the learning process and evaluating his or her actions. Eventually, they become less dependent on others and likewise on the contextual features in any learning situation (McCaslin, 2004).

Self-regulated learning strategies can be considered as a welldefined collection of cognition, motivational and behavioral tactics that can be used by learners to manage their learning processes (Stephens: 2009). The effective use of SRL strategies is a skill necessary for student success in online learning environments (Barnard -Brak, Paton, \& Lan, 2010). Advanced devices (e.g., smart phones) promote the ubiquitous use of Google apps. Therefore, using Google apps, students can share thoughts about their SRL processes promptly. Therefore, SRL theory supports the exploration of the relationship between students' ability to increase selfregulated learning skills and learning outcomes (Quince, 2013) that promote student success in online environments, which were examined in this study.

Improving SRL skills and using its strategies are of great interest to learning researchers and practitioners, since self-regulated learning is critical to students' academic success (Bernard, et al., 2009; Kistner, et al., 2010).

A model for self-regulated learning in technology education typically includes three main dimensions (Barak: 2010):

1. Cognition: Learning, Problem-solving, Creativity.

2. Meta-Cognition: Goal setting, Self-monitoring, Reflective practice.

3. Motivation: Interest, Intrinsic motivation, Self-efficacy beliefs.

A study of Ertuğrul (2011) confirmed that self-regulated learning raises skill levels of students in online learning environments are high. There may be several factors for web-based education to become successful. One of them is self-regulated learning skills, which is seen to be an important variable in terms of success in online learning environments. (Ertuğrul, 2011)

Kwangsu (2013, p. 628) considers self-regulated skills as containing: planning, monitoring, reflecting, using learning strategies, seeking assistance, aiding, providing support for the SRL processes of others such as planning, monitoring, reflecting. Therefore, as Järvelä 
(2007) self-regulated learning focuses on an individual as a regulator of a behavior and refers to the process of becoming a strategic learner by regulating their cognition, motivation and behavior to optimize learning, but there is another conceptualizing self-regulated learning as a coregulation has been influenced by socio-cultural theory and it emphasizes the gradual appropriation of shared problems and tasks through interpersonal interaction.

Therefore, in this study, we explored how using SRL strategies like strategies for the regulation of academic cognition, strategies for the regulation of academic motivation, strategies for the regulation of behavior and context) are effective for learners to apply SRL skills in an actual learning environment using Google apps.

\section{Research procedures:}

\section{A-Sample of Research:}

- Pilot sample: 20 of master's students in faculty of specific education to ensure the psychometric characteristics of the research tools (validity and reliability).

- Basic sample: 60 of master's students in faculty of specific education. The sample divided in two equal groups, each one contains of 30 students, group 1 teach in individual method, group 2 teach in cooperation method. The two groups were selected and distributed in randomly.

\section{B- Research tools:}

- Observation Skills checklist of using Google Applications (prepared by researchers).

- Self- Regulated Learning Strategies Scale (prepared by the researchers).

\section{C- Basic experimentation steps:}

- Preparing observation skills checklist: The target of checklist: testing the development of student's skills on using Google Applications in education:

○ Preparing the main and the sub skills list: by reviewing many previous researches (Denton,2012; Lindenberg, 2011; ICIT,2014).

- The validity of the checklist: the checklist was reviewed by specialists to ensure that it measures the skills performance of using the Google Applications in education from the master's students; they agreed with (80-100\%) percent about the validity and availability of using this checklist in to measure the targeted skills.

- The stability of the checklist: the checklist was tested by using "Cooper equation" through the way of measuring the percent of 


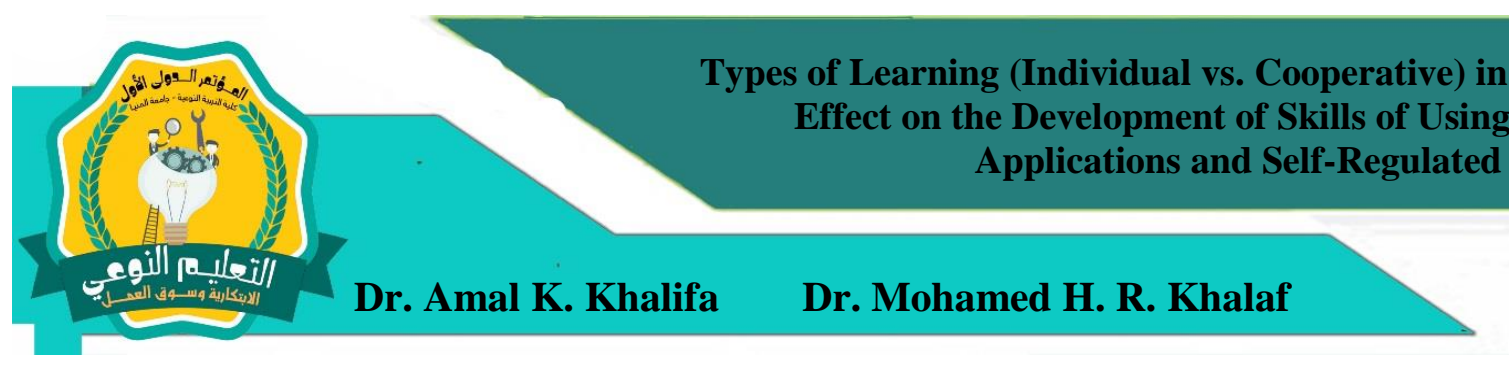

agreement between the observers (the researcher and two teaching staff members). After noticing ten students from the exploratory sample, then calculate the percentage of agreement between the observers, which ranged from $(85.17 \%$ to $93.33 \%)$ and show an acceptable level of stability.

- Preparing the self-Regulated learning scale: the target of the scale: Selfregulated learning scale was based on the study strategies used in an academic course to support learning using Google application on a mobile individually and cooperatively. Selecting the scale phrases: When preparing the scale, the researchers reviewed the following researches: Barnard-Bra (2010), Wolters (2003), Quince (2014), and Al-husinan (2010) According to the previous researches, the statements of the scale were developed according to the following strategies. The table below shows the strategies and the statement for each strategy:

Table (2): Strategies at Self-Regulated Learning Scale

\begin{tabular}{ll}
\hline \hline Strategies & Statements \\
\hline Frist: Strategies for the regulation of academic cognition: & $1,2,3,4,5,56$ \\
Rehearsal. & $6,7,8,9,48,53,65$ \\
Elaboration & $10,11,12,81$ \\
Organization. & $13,14,15,16,17,18,19,20,21,38,46,47$ \\
Metacognitive self-regulation. & $, 57 *, 58,64$ \\
Second: Strategies for the regulation of academic motivation: & $22,23,24,25,37,82$ \\
Mastery self-talk strategy. & $26,35,54 *, 71$ \\
Performance/Extrinsic self-talk. & $36,40,44,45$ \\
Performance/Relative ability self-talk. & $43,66,67$ \\
Relevance Enhancement strategy. & $55,59,62$ \\
Situational interest enhancement strategy. & $27,28,49$ \\
Environmental control strategy. & $41^{*}, 42,51 *, 52,70,74$ \\
Third: Strategies for the regulation of behavior and context: & $32,33,60,61,63,68,72,73,75,76$ \\
Effort regulation. & $29,30,31,83,84$ \\
Regulating time. & $34,39,50,69,77,78,79,80$ \\
Peer learning. & Help - seeking.
\end{tabular}

*it represented the negative statements in scale.

○ The validity of the Self- Regulated Learning Scale: The Scale was reviewed by specialists to ensure the validity and availability of it to measure the ability of self-regulated learning on the targeted master's students. The jury agreed with (87-100\%) percent about the validity and availability of using this scale to measure the targeted 
ability.

- The stability of the Self-Regulated Learning Scale: the scale was tested by using "Cronbach's Alpha"; it has reached to (0.719), which shows an acceptable level of stability.

\section{D- Equality of the two experimental groups:}

To test the equality of the two experimental groups in the dependent variables (Skills of using Google Application and the ability of SelfRegulated learning), that must be checked after using the independent Variables (the two types of Implementing the mobile learning model Individual \& Cooperative). The researchers used t-test to achieve that in both tools "Checklist \& Self-Regulated scale" to maintain the difference between the two groups in the pretest. The result is shown in the tables $(3,4)$ as below:

Table (3): Comparison between the two studied groups according to Skills checklist

\begin{tabular}{|c|c|c|c|c|c|c|}
\hline \multirow[t]{2}{*}{ checklist } & \multicolumn{2}{|c|}{$\begin{array}{l}\text { Co-operation group } \\
\qquad(\mathrm{n}=30)\end{array}$} & \multicolumn{2}{|c|}{$\begin{array}{l}\text { Single group } \\
\quad(\mathrm{n}=30)\end{array}$} & \multirow[t]{2}{*}{$\mathrm{t}$} & \multirow[t]{2}{*}{$\mathrm{p}$} \\
\hline & Mean & SD. & Mean & SD. & & \\
\hline Before & 79.12 & 3.51 & 77.85 & 4.65 & 1.192 & 0.238 \\
\hline
\end{tabular}

It is clear from the previous table (3) that there is no statistically significant difference between the two studied groups in the checklist, which shows the equivalence between the two groups in the pre implementing of the independent variables.

Table (4): Comparison between the two studied groups according to self-regulated learning scale

\begin{tabular}{ccccccc}
\hline \hline \multirow{2}{*}{ SRL } & \multicolumn{7}{c}{ Co-operation group $(\mathrm{n}=$} & \multicolumn{2}{c}{ Single group $(\mathrm{n}=$} \\
& Mean & SD. & Mean & SD. & & $\mathrm{t}$ \\
\hline Before & 107.77 & 7.46 & 105.0 & 4.69 & 1.719 & 0.091 \\
\hline \hline
\end{tabular}

It is clear from the previous table (4) that there is no statistically significant difference between the two studied groups in the Self-regulated scale, which shows the equivalence between the two groups in the pre implementing of the independent variables.

\section{E-Preparing the experimental treatments and implementing them:}

- Inviting (60) students (the basic sample of the research) to create accounts in WhatsApp by using their iPhone.

- Creating a group in WhatsApp called "Cooperation Group" and inviting (30) students to participate in that group.

- preparing videos about the targeted skills of using Google Application in education.

- Sharing produced videos to 60 participated students, 30 (group1) in 
individual way by using the personal account for everyone in WhatsApp, another 30 (group2) in cooperation way by using the created group in WhatsApp "Cooperation Group".

- Asking the individual group members to do the assignments individually and sending the productions to the researchers by using WhatsApp accounts.

- Asking the cooperation group members to do the assignments cooperatively and sharing the productions to themselves and to the researchers by WhatsApp group and the google Apps itself.

- Evaluating group (1) individually in the lab by asking them to do the tasks by using the targeted google Apps, and the researchers observing them by using the produced checklist. Then the researchers ask them to do the SRL scale.

- Evaluating group (2) individually in the lab by asking them to do the tasks by using the targeted google Apps, and the researchers observing them by using the produced checklist. Then the researchers ask them to do the SRL scale.

\section{Results:}

To answer question one "What is the effect of the two types of learning on the development of skills of using Google educational applications?", the researchers ran the t-test between the two groups (individual vs. cooperation) and obtained the effect size of the difference between these groups in checklist as shown in the table (5) below:

Table (5): Comparison between the two studied groups according to the checklist

\begin{tabular}{|c|c|c|c|c|c|c|c|}
\hline \multirow{2}{*}{ checklist } & \multicolumn{2}{|c|}{$\begin{array}{l}\text { Co-operation group } \\
\qquad(\mathrm{n}=30)\end{array}$} & \multicolumn{2}{|c|}{$\begin{array}{l}\text { Single group } \\
\quad(\mathrm{n}=30)\end{array}$} & \multirow{2}{*}{$\mathrm{t}$} & \multirow{2}{*}{$\mathrm{p}$} & \multirow{2}{*}{$\begin{array}{l}\text { Effect size } \\
\quad(\eta 2)\end{array}$} \\
\hline & Mean & SD. & Mean & SD. & & & \\
\hline After & 524.33 & 18.35 & 481.78 & 17.59 & $9.170 *$ & $<0.001 *$ & $0.592 \#$ \\
\hline
\end{tabular}

\footnotetext{
t: Student t-test between the two groups

* Statistically significant at $\mathbf{p} \leq$

0.05

\# Large Effect
}

It can appear from the previous table (5):

1- The means of two groups are bigger than 75\% (412.5) of total degree (550.5) of the checklist, which refers to the effectiveness of the mobile learning model Regardless the methods of mobile learning implementation.

2- There is statistically significant difference at the level of (0.05) between the two studied groups in the checklist, For the benefit of the group2 (Cooperation group) with large effect size (0.592). Therefore, the 
researchers reject the first hypothesis, and interpreted this result in the light of the group work features, which helped all students to practice the targeted skills in a high quality, while the excellent students hindered weakness students, and in additionally to many of features which were presented in the theoretical framework section above.

This result agreed with the results of previous researches like Huang (2014), who confirmed that the group cooperation method was better than individual learning using Tablet PCs, Google+, etc., Even though some of the low-achievement students stated that these were difficult, they were able to discuss their problems with their partners, which resulted in a higher sense of accomplishment and participation. The result is also in agreement with the study of Möller (2012) which found that mobile applications focus on cooperative learning, and the study of Wang (2013) which suggested that e-cooperative learning with mobile networking apps promoted a social constructivist learning environment, which renders the need for the newly acquired knowledge evident and perceived as useful to the students, which ensures the cooperative method effectiveness when compared with the individual method.

To answer question two "What is the effect of the two types of learning on the development of self- regulated learning", the researchers ran the t-test between the two groups (individual vs. cooperation) and obtained the effect size of the difference between these groups in selfregulated learning scale as shown in the table (6) below:

Table (6): Comparison between the two studied groups according to self-regulated scale

\begin{tabular}{cccccccc}
\hline \hline SRL & \multicolumn{2}{c}{ Co-operation group } & \multicolumn{2}{c}{ Single group } \\
& Mean $(\mathrm{n}=30)$ & SD. & Mean & SD & & t & Effect \\
& size $(\eta 2)$ \\
\hline After & 216.20 & 17.44 & 203.90 & 23.91 & $2.276^{*}$ & $0.027^{*}$ & $0.082 \#$ \\
\hline
\end{tabular}

t: Student t-test between the two groups

* Statistically significant at $\mathbf{p} \leq \mathbf{0 . 0 5}$

\# Large Effect

It can appear from the previous table (6):

1- The means of two groups are bigger than $75 \%$ (183) of total degree (244) of the self-regulated scale, which refers to the effectiveness of the mobile learning model regardless of the methods of mobile learning implemented.

2- There is statistically significant difference at the level of (0.05) between the two studied groups in the self-regulated scale, For the benefit of the 
group2 (Cooperation group) with intermediate effect size (0.082). Therefore, the researchers reject the second hypothesis, and interpreted this result in the light of the group work features, which helped all students to develop their ability of self-regulated learning, while the excellent students in the self-regulation hindered weakness students, in addition to many of features which presented in the theoretical framework section above.

3- However, the effect is intermediate because both groups (individual vs. cooperation) have used self-regulation learning, but the mean of cooperation group (216.20) is higher than individual (203.90).

This result agreed with the results of previous researches like the results of Järvelä (2007) which concluded that the Mobile Mind Map tool study implied that the tool can be used for enhancing co-regulation in terms of sharing and externalizing visual knowledge representations and developing them in interpersonal interactions, and the results showed that construction and sharing of knowledge representations activated students' self-regulated learning; explaining and elaborating their own understanding. Moreover, Cheong (2012) proposed the framework for using mobile apps and cooperative learning theories in a lecture environment to promote higher order thinking skills in learners. The result is also in agreement with the study of Mukherjee (2014), where the authors developed a course-based mobile application that contains different web tools that help students learn the course material and a social networkbased discussion forum where peers can share their views to enhance cooperative learning, which ensures the cooperative method effectiveness when compared with the individual method.

To answer the question three "What is the significance of the correlation between the scores of students in each of the checklist of the google Apps skills and self-regulated learning scale?", the researchers ran the Pearson Correlation Coefficient between the two research tools as shown in the table (7) below:

Table (7): Correlation between note care and Self-organization scale in each group after program

\begin{tabular}{ccc}
\hline \hline Research Groups & $\mathrm{r}$ & $\mathrm{p}$ \\
\hline Co-operation group $(\mathrm{n}=30)$ & $0.678^{*}$ & $<0.001^{*}$ \\
Single group $(\mathrm{n}=30)$ & $0.451^{*}$ & $0.012^{*}$ \\
\hline \hline
\end{tabular}

r: Pearson coefficient

*: Statistically significant at $\mathbf{p} \leq \mathbf{0 . 0 5}$

It is clear from the previous table (7) that here is a statistically 
significant positive correlation at the level (0.05) between the scores of students in each of the checklist and self-regulated learning scale in the both two groups. Therefore, the researchers rejected the third hypothesis, and interpreted this in the light of the proposal that the two types of learning (individual vs. cooperative) in mobile devices are effective as to the development of skills of using Google educational applications and selfregulated learning. However, the Cooperation group score (0.678) is higher than that of the Single group (0.451) because cooperation among students to implement the duties leads to developing the skills of using Google educational applications and self- regulated learning better than Single group. Yet the two types of learning (individual vs. cooperative) in mobile devices are effective as to the development of skills of using Google educational applications and self-regulated learning.

\section{Recommendations:}

Employment of Google apps in education, by using Google Docs, Google slides, Google Drawing, Google Forms and Google Sheets, Employment of mobile device and its applications in education, which benefits students spatially separated from study locations, and Making use of cooperative learning strategies in teaching, especially in the field of educational technology.

\section{References:}

Ainsa, T. (2013). Early Childhood Pre-Service Teachers' Response to Mobile Technology: Creative Projects, Analysis, and Reflection on Learning Experiences, Education Vol. 134 No. 2, 161-166.

Alhusinan, I. A. (2010). Self- Regulated Learning Strategies in the Light of Pintrich's Model and Their Relationship to Achievement, Specialization, Academic Level, and the Preferred Learning Styles, Dissertation of Doctor of Psychology, Saudi Arabia, University of Imam Muhammad bin Saud Islamic University.

Ally, M. (2009). Mobile learning: Transforming the delivery of education and Training, Athabasca University Press.

Almasri, R. (2013). The Use of Mobile Technology in Education by International Students in United States Universities: Perceptions Regarding Mobile Applications for English Language Learning, Doctor of Science in Information System and Communications.

Banyard, B.; Underwood, J. (2011). Self-Regulated Learning in Technology Enhanced Learning Environments in Europe: Facilitators and Barriers to Future Development, 155-163.

Barak, M. (2010). Motivating self-regulated learning in technology 
education, Int J Technol Des Educ 20:381-401, Springer.

Baran, E. (2014). A Review of Research on Mobile Learning in Teacher Education. Educational Technology \& Society, 17 (4), 17-32.

Barnard-Brak, L.; Lan, W. Y.; Paton, V. O. (2010). Profiles in SelfRegulated Learning in the Online Learning Environment, International Review of Research in Open and Distance Learning Volume 11, Number 1. 62-80

BenMoussa, C. (2003). Workers on the move: new opportunities through mobile commerce, Presented at the Stockholm Mobility Roundtable, May 22-23.

Bernard, L.; Lan, W. Y.; To, Y. M.; Paton, V. O.; Lai, S. L. (2009). Measuring self- regulation in online and blended learning environments. The Internet and Higher Education, 12, 1-6.

Bonham, S. (2011). Whole class laboratories with Google Docs. Physics Teacher, 49(1), 22-23.

Brazuelo, F.; Gallego, D. (2011). Mobile Learning, Los dispositivos móviles Como recurso Educativo. Sevilla: Eduforma.

Cheon, J., Lee, S., Crooks, S. M., \& Song, J. (2012). An investigation of mobile learning readiness in higher education based on the theory of planned behavior. Computers \& Education, 59(3), 1054-1064.

Cheong, C.; Bruno, V.; Cheong, F. (2012). Designing a Mobile- app-based Collaborative Learning System, Journal of Information Technology Education: Volume 11, 2012 Innovations in Practice, 97-119.

Cho, M.; Cho, K. (2013). Training of self-regulated learning skills on a social network system, Springer, Soc Psychol Educ 16, 617-634.

Cochrane, T.; Bateman, R. (2010). Smartphones give you wings: pedagogical affordances of mobile Web 2.0., Australasian Journal of Educational Technology, 26(1), 1-14.

Denton, D. W. (2012). Enhancing Instruction through Constructivism, Cooperative Learning, and Cloud Computing, TechTrends, Volume 56, Number 4, 34-41.

Dessoff, A. (2010). Google and Microsoft go to school, District Administration. www.DistrictAdministration.com, September, 61-66. Ford, N.; Bowden, M.; Beard, J. (2011). Learning together: using social media to foster collaboration in higher education. In L. A Wankel and C. Wankel (Eds.), Higher Education Administration with Social Media: Cutting-edge Technologies in Higher Education, 2, 105-126. Fuegen, S. (2012). The Impact of Mobile Technologies on Distance Education, 56(6) Tech Trends, 49-53. 
Hochstrasser, J. L. (2014). The Use of Technology for Enhancing the Learning Experiences of Undergraduate Students: From Online Education to the Use of Mobile Devices and Web-Based Programs, Dissertation of Doctor of Education, College of Graduate Studies, University of Idaho, United States, Published by Pro Quest LLC.

Huang, Y. M.; Liao, Y. W.; Huang, S. H.; Chen, H. C. (2014). A Jigsawbased Cooperative Learning Approach to Improve Learning Outcomes for Mobile Situated Learning. Educational Technology \& Society, 17 (1), 128-140.

Huang, Y. M.; Huang, T. C.; Hsieh, M. Y. (2008). Using annotation services in a ubiquitous Jigsaw cooperative learning environment. Educational Technology \& Society, 11(2), 3-15.

ICIT (2014). google apps an overview of google apps and program features ICIT Technology Training and Advancement, University of Wisconsin.

Järvelä, S.; Näykki, P.; Laru, J.; Luokkanen., T. (2007). Structuring and Regulating Collaborative Learning in Higher Education with Wireless Networks and Mobile Tools. Educational Technology \& Society, 10 (4), 71-79.

Johnson, L.; Adams Becker, S.; Estrada, V.; Freeman, A. (2014). NMC horizon report: 2014 higher education edition. Austin, Texas: The New Media Consortium.

Ju Joo, Y.; Bong, M.; Choi, H. (2000). Self-Efficacy for Self-Regulated Learning, Academic Self-Efficacy, and Internet Self-Efficacy in WebBased Instruction, ETR\&D, 48 (2), 5-17.

Kearney, M.; Maher, D. (2013). Mobile learning in math teacher education:

Using iPads to support pre-service teachers' professional development. Australian Educational Computing, 27(3), 76-84.

Keser, H.; Uzunboylu, H.; Ozdamli, F. (2011). The trends in technology supported collaborative learning studies in 21st century, World Journal on Educational Technology, 3(2), 103-119.

Keskin, N.O.; Metcalf, D. (2011). The current perspectives, theories, and practices of mobile learning, The Turkish Online Journal of Educational Technology, 10(2), 202-208. Retrieved from: http://www.ebscohost.com

Kistner, S.; Rakoczy, K.; Otto, B.; Ewijk, C. D.; Büttner, G.; Kliema, E. (2010). Promotion of self-regulated learning in classrooms: Investigating frequency, quality, and consequences for student performance. Metacognition and Learning, 5, 157- 171. 
Kook, J. (2014). Students' behavioral intention toward adoption of mobile learning in higher education, International Journal of Instructional Technology and Distance Learning, 11(10), 45-54

Lindenberg, K. (2011). Press release: Pearson Cloud Connect now available for Google Apps for education. E School News. Retrieved from http://www.eschoolnews.com/

López, Á.; María, J.; Almendros, M.; Segura, M. (2013). Mobile learning technology based on iOS devices to support students with special education needs, Computers \& Education 61, 77-90.

McCaslin, M. (2004). Coregulation of opportunity, activity, and identity in student motivation. In D. McInerney \& S. Van Etten (Eds.), big theories revisited: Research on sociocultural influences on motivation and learning, Greenwich, CT: Information Age, 249-274.

Messeguer, R.; Navarro, N.; Reyes, A. (2008). Group-awareness for Mobile Cooperative Learning, IEEE, Fourth IEEE International Workshop on Wireless, Mobile and Ubiquitous Technology in Education.

Möller, A.; Beege, B.; Kranz, M. (2012). MobiDics: Cooperative Mobile E-Learning for Teachers.

Motiwalla, L. F. (2007). Mobile learning: A framework and evaluation, Computers \& Education 49, 581-596.

Mukherjee, P.; et al (2014). Designing a Mobile and Socially Networked Learning Assistant for a University-level Keyword Advertising Course, MERLOT Journal of Online Learning and Teaching. 10(3), 351-373.

Navaridas, F.; Santiago, R.; Tourón, J. (2013). Opinions from teachers in the Fresno area of Central California regarding the influence of mobile technology on their students' learning. RELIEVE, 19(2), 4-10.

Ovidia, S. (2012). Heritage conservation in secondary education curriculum: A didactic proposal based on the application of ICT, Procedia - Social and Behavioral Sciences 51, 782 - 786.

Pintrich, P. R. (2000). The role of goal orientation in self-regulated learning. In M. Boekaerts, P. Pintrich, \& M. Zeidner (Eds.), Handbook of self-regulation, 451- 502 .

Quince, B. (2013). The Effects of Self-Regulated Learning Strategy Instruction and Structured-Diary Use on Students' Self-Regulated Learning Conduct and Academic Success in Online CommunityCollege General Education Courses, University of San Francisco USF Scholarship Repository, Doctoral Dissertations. 


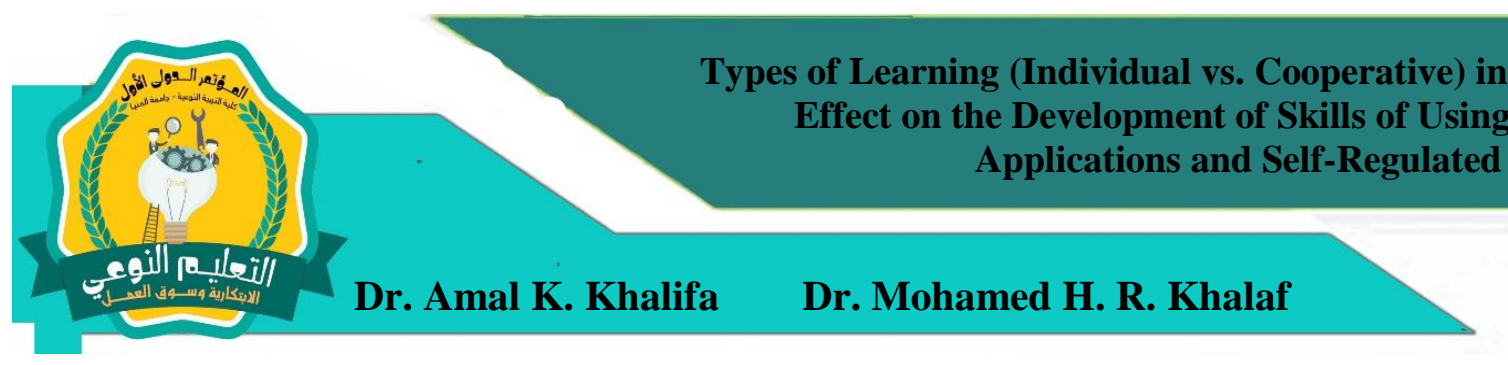

Rau, P.; Gao, Q.; Wu, L. (2008). Using mobile communication technology in high school education: Motivation, pressure, and learning performance, Computers \& Education, 50, 1-22.

Revere, L.; Kovach, J. (2011). Online technologies for engaged learning: A meaningful synthesis for educators. Quarterly Review of Distant Learning, 12(2), 113-124.

Shunye, W. (2014). A new M-learning system for higher education, Journal of Chemical and Pharmaceutical Research, 6(7),1301-1307.

Stephens, A. (2009). Effects of Using Weekly External Goal Planning Forms in Developing Learners' Self-Regulated Learning Skills in an Online Course, Doctor of Philosophy, Capella University.

Tenally, T. (2014). Google Apps for Education: Frequently Asked Questions, Fairfax County, Virginia.

Usta, E. (2011). The Examination OF Online Self-Regulated Learning Skills In web-based Learning Environments in Terms of different Variables, TOJET: The Turkish Online Journal of Educational Technology, 10(3), 278-286.

VAZQUEZ-CANO, E. (2014). Mobile Distance Learning with Smartphones and Apps in Higher Education, Educational Sciences: Theory \& Practice, 14(4), 1505- 1520.

Wang, J. (2013). Perceptions of mobile assisted e-cooperative Learning Quality, Asian Journal of Social Sciences \& Humanities, 2 (3), 11-20. Wolters, C. A.; Pintrich, P. R.; Karabenick, S. A. (2003). Assessing Academic Self-Regulated Learning, Paper prepared for the Conference on Indicators of Positive Development: Definitions, Measures, and Prospective Validity, Sponsored by ChildTrends, National Institutes of Health, March 12-13.

Zusho, A. \& Pintrich, P. R. (2007). Student Motivation and Self-Regulated Learning in The College Classroom, Springer, 731-810

7things you should know about Google Apps (2008). Google Applications for Education available online at: http://learn.googleapps.com/ 